\title{
De términos de partes a términos de clases: La gramaticalización de merónimos en clasificadores nominales en yanomama
}

\author{
From part terms to class terms: Grammaticalization \\ of meronyms in noun classifiers in Yanomama
}

Helder Perri Ferreira ${ }^{2}$

\begin{abstract}
Resumen
Los términos que indican partes son una importante fuente de gramaticalización de los clasificadores nominales en yanomama. Este trabajo investigará uno de los caminos que recorren los nombres de partes hasta que se convirtieran en clasificadores. Este camino empieza con un mecanismo lexicogénico de la lengua que hace uso de la construcción todoparte para designar metafóricamente no a partes de entidades, sino a entidades completas. Formalmente, esta construcción no se distingue de los sustantivos con clasificadores. En particular, los términos de partes en esas construcciones metafóricas se encuentran en la misma posición morfosintáctica de un clasificador nominal. Esa circunstancia dio espacio a que ocurrieran procesos de resemantización de los merónimos y permitió que algunos de éstos, además de las propiedades formales, adquirieran asimismo los rasgos semánticos de un típico clasificador.

Palabras-clave: Clasificadores nominales. Partes del cuerpo. Construcciones todo-parte. Metáfora. Gramaticalización.
\end{abstract}

\begin{abstract}
Terms for body parts are an important source of grammaticalization of noun classifiers in Yanomama. This work will describe one of the paths that part terms have followed in becoming a classifier. This path begins with a lexicogenic mechanism found in the language that makes use of a whole-part construction, in a metaphorical sense, to name not parts of entities, but whole entities. This construction is not formally distinguishable from a noun with a classifier. In particular, the body part terms in these constructions occupy the same morphosyntatic position reserved for noun classifier. This circumstance gave room for later ressemantization processes of the meronyms that eventually allowed some of them to gain, not only the morphosyntatic properties of a classifier, but also the semantic features of a typical one.
\end{abstract}

${ }^{1}$ Variedad del grupo yanomam de la familia yanomami, hablada en la región de Papiu, Roraima, Brasil.

2 PhD Candidate at Radboud Universiteit. Bolsista CAPES - Proc. no. 0944/12-2. CAPES Foundation, Ministry of Education of Brazil, Brasilia - DF 70040-020, Brazil. Parte del contenido de este artículo fue previamente trabajado en "Los Clasificadores del Yanomama del Papiu", tese de maestría defendida en 2009 por este mismo autor en el Centro de Investigaciones y Estudios Superiores en Antropología Social (CIESAS). Email: helderperri@yahoo.com.br. 
Keywords: Noun classifiers. Body part terms. Whole-part constructions. Metaphor. Grammaticalization.

\section{Presentación}

El yanomama (YMA) presenta por lo menos tres subclases de sustantivos que son identificables por sus propiedades morfosintácticas y semánticas: los holónimos no clasificados (sustantivos del Tipo 1) que son morfemas libres en la lengua; los merónimos (sustantivos del Tipo 2) que son clíticos; y los holónimos clasificados (los sustantivos del Tipo 3 o sustantivos con clasificadores), que son palabras complejas compuestas de dos elementos léxicos: un morfema libre y un clítico que indica la clase a la que pertenece el referente del sustantivo.

\section{TIPO 1}

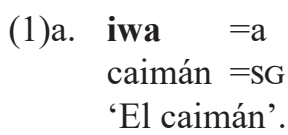

b. thuwë $=\mathrm{a}$

mujer $=$ SG

'La mujer'.

c. moka $=\mathrm{a}$

rana $=$ SG

'La rana'.
TIPO 2

(2)a. iwa =xina
caimán =cola
'La cola del caimán'.

b. thuwë =yamaka

mujer $=$ oreja

'La oreja de la

mujer'.

c. moka =imiki

rana $=$ mano

'La mano de la rana'.

\section{TIPO 3}

(3)a. $\mathbf{m a u}=\mathbf{u}$

agua $=$ CLN:líquido

'El agua'

b. naxi $=$ koko

yuca $=$ CLN:esférico

'Yuca'.

c. mai $=$ si

asaí $=$ CLN:palmera

'Palmera de asaí'.

Hay todavía un cuarto tipo de sustantivo del YMA: una composición del tipo todo-parte, entre un sustantivo del Tipo 1 (holónimo no clasificado) y un sustantivo del Tipo 2 (merónimo), usada con sentido metafórico para nombrar no a partes sino a entidades completas. Este es un mecanismo particularmente productivo en la creación de nombres para los objetos del contacto con la sociedad brasileña, (4a) y (4d), pero también es identificable en algunos nombres de referentes más "tradicionales", como algunos animales (4d), frutos (4b) y plantas de la selva (4c), lo que indica alguna profundidad histórica para el fenómeno ${ }^{3}$.

\footnotetext{
${ }^{3}$ Las abreviaciones usadas en este trabajo son: A - agente; CLN - clasificador nominal; DERIV - derivativo; DIN - dinámico; DISTR - distributivo; DL - dual; ERG - ergativo; EST estativo; GEN - genitivo; LIG - ligadura; LIT. - literalmente; NEG - negación; P - paciente; PAS - pasado; PERF - perfectivo; PRES - presente; PL - plural; POS - posesivo; SG - singular; $\mathrm{S}-$ sujeto.
} 


$$
\begin{aligned}
& \text { (4)a. iwa =xina } \\
& \text { caimán =cola } \\
& \text { 'El serruche' } \\
& \text { (lit. 'cola de caimán'). }
\end{aligned}
$$

b. warõ =wathëmo

hombre =testículo

'Un fruto (Tabernaemontana sp)'.

(lit. 'testículo de hombre').

$$
\begin{aligned}
& \text { c. moka =imiki } \\
& \text { rana =mano } \\
& \text { 'Planta medicinal'. } \\
& \text { (lit. 'La mano de la rana'). }
\end{aligned}
$$
d. pore =mamakasi
fantasma =párpado
'Luciérnaga', 'linterna'.
(lit. 'párpado de fantasma').

En este trabajo, voy a mostrar que las propiedades formales de este cuarto tipo de sustantivo no difieren de las de los sustantivos con clasificadores (Tipo $3)$. En efecto, voy a argumentar que parte del paradigma de los clasificadores nominales en YMA proviene de los sustantivos merónimos (Tipo 2) y mostraré que uno de los caminos de gramaticalización de esos sustantivos en CLN es precisamente la construcción todo-parte usada en sentido metafórico. Voy a argumentar asimismo que ese proceso es responsable también por la semántica opaca de parte del paradigma de los CLN, sugiriendo que esas formas son merónimos en construcciones metafóricas fosilizadas, cuyo significado extendido se ha perdido para los hablantes contemporáneos.

Empezaré señalando, en el apartado 2, las propiedades definitorias de cada una de las subclases de sustantivos en YMA e indicaré los tipos semánticos generalmente asociados a cada una de ellas. En el apartado 3, presentaré la construcción todo-parte usada metafóricamente para nombrar entidades completas, analizaré la estructura semántica de esas metáforas y mostraré que morfosintácticamente esas construcciones se asemejan a un sustantivo con clasificador. Por fin, en el apartado 4, argumentaré que esa indistinción formal entre merónimo en construcción metafórica y CLN permitió que algunos merónimos adquirieran también rasgos y propiedades semánticas típicas de un CLN. Estudiaré un caso ejemplar de gramaticalización completa de un merónimo (=na 'diente') en el CLN usado con avispas, abejas, hormigas y ortigas.

\section{Tres tipos de sustantivos en YMA}

El primer tipo de sustantivos se define semánticamente por agrupar palabras que prototípicamente denotan a entidades discretas e independientes (holónimos) mientras que el segundo tipo reúne sustantivos que tienen como referentes las partes de esas entidades discretas o entidades que son concebidas como dependientes de otras entidades (merónimos). En el Cuadro 1 presento en la algunos sustantivos del Tipo 1 (entidades completas) y en el Cuadro 2 la un breve listado de sustantivos del Tipo 2 (partes de las entidades). 


\section{Cuadro 1 - Los sustantivos del Tipo 1 (Holónimos)}

\begin{tabular}{|l|l|l|l|l|l|}
\hline apiama & 'avión' & mayapa & 'tucán' & tihi & 'jaguar' \\
\hline arima & 'periquito' & mokawa & 'escopeta' & uhuru & 'niño' \\
\hline haya & 'venado' & moko & 'muchacha' & warõ & 'hombre' \\
\hline hayokoroma & 'hacha' & mothaka & 'sol' & watori & 'viento' \\
\hline hee & 'murciélago' & napë & 'extranjero' & werehe & 'perico' \\
\hline hehu & 'cerro' & oxe & 'niño' & wii & 'canasto' \\
\hline hiima & 'perro' & pata & 'adulto' & xahema & 'atizador' \\
\hline yuri & 'pez' & pixata & 'tierra' & xama & 'tapir' \\
\hline hiya & 'muchacho' & poo & 'cuchillo' & xaraka & 'flecha' \\
\hline koraha & 'plátano' & poripa & 'luna' & yanomama & 'ser humano' \\
\hline krokekroke & 'nube' & thuë & 'mujer' & yaro & 'animal' \\
\hline
\end{tabular}

\section{Cuadro 2 - Los sustantivos del Tipo 2 (Merónimos)}

\begin{tabular}{|c|c|c|c|c|c|}
\hline$=$ ãmo & 'hígado' & $=$ makasi & 'ombligo' & $=$ nahasi & 'uña (mano)' \\
\hline$=$ hana & 'hoja' & $=$ mamo & 'ojo’' & $=n a k a$ & 'vagina' \\
\hline$=$ hoko & 'frente' & $=m a h u k u$ & 'pie' & $=$ nasipë & 'orina' \\
\hline$=$ homothoki & 'columna' & $=$ matha & 'pantorrilla' & $=$ pari $k i$ & 'pecho' \\
\hline$=$ hoxo & ‘pico' & $=$ maxikopë & 'riñones' & $=p i h i k i$ & 'rostro' \\
\hline$=h r i k i$ & 'lomo’ & $=$ maxiopë & ‘corazón' & $=$ poko & 'brazo' \\
\hline$=$ humapë & 'espalda' & $=$ mayo & 'rastro' & $=s i$ & 'piel' \\
\hline$=i m i$ & 'dedo (mano)' & $=m o$ & 'semilla' & $=$ wathëmo & 'testículo' \\
\hline$=k a h i k i$ & 'boca' & $=$ mоирё & 'esperma' & $=x i n a$ & 'cola' \\
\hline$=$ kanasi & 'resquicios' & $=$ moxi & 'pene' & $=y a m a k a$ & 'oreja' \\
\hline$=$ maheko & 'rodillas' & $=n a$ & 'diente' & $=y \tilde{r} r a$ & 'cuerno' \\
\hline
\end{tabular}

Así como los sustantivos del Tipo 1, los sustantivos del tercer tipo (los sustantivos con clasificadores) también denotan entidades completas, pero con la diferencia de que en este caso el referente es parte de un conjunto mayor dentro de la perspectiva de los hablantes del YMA. Esta relación de pertenencia se indica por medio de los CLN. La gran parte de los sustantivos con referentes 
clasificados son de los reinos vegetal e de los hongos ('hongo', 'árbol', 'palmera', 'fruto en vaina larga', 'fruto con semilla útil' etc.), (cf. Cuadro 3), y una parte menos numerosa del reino animal ('abeja/avispa', 'serpiente', 'pájaros con pluma característica', 'carpinteros' etc.) (cf. Cuadro 4). Sin embargo, hay diversos sustantivos que representan entidades inanimadas (y no vegetales) que reciben CLN. En esos casos, el CLN representa una categoría en la que se inscriben los referentes principalmente según su forma o sustancia (cf. Cuadro 4).

\section{Cuadro 3 - Sustantivos del Tipo 3 con CLN transparentes (I)}

\begin{tabular}{|c|c|}
\hline$=h i$ & árboles \\
\hline$a h \tilde{o} i=h i$ & 'árbol de aguacate' \\
\hline rokoroko $=h i$ & 'árbol de papaya' \\
\hline$k \tilde{a} i=h i$ & 'tipo de inga' \\
\hline pahi $=h i$ & 'tipo de inga' \\
\hline mukuru $=h i$ & 'árbol medicinal' \\
\hline$=s i$ & palmeras \\
\hline$\ddot{e} r i \quad s i$ & palmera de cumare \\
\hline kõanari $=s i$ & palmera de batauá \\
\hline$k u i=s i$ & palmera de burití \\
\hline$m a i=s i$ & palmera de asaí \\
\hline rasa $=s i$ & palmera de pijiguao \\
\hline rihoari $=s i$ & palmera de yacaratia \\
\hline$=$ thotho & lianas \\
\hline riporiporima $=$ thotho & liana usada como cuerda \\
\hline akanasima $=$ thotho & liana usada como cuerda \\
\hline apasi $=$ thotho & liana medicinal \\
\hline naxuruma = thotho & liana de maracuyá \\
\hline horokotho =thotho & liana de jícaro, porongo \\
\hline$=$ ãmo & hongos \\
\hline arra $=$ amo & hongo comestible \\
\hline hramirima $=$ amo & hongo comestible \\
\hline (riã) moxirima $=a m o$ & hongo comestible \\
\hline pihi waiyorema $=$ amo & hongo no-comestible \\
\hline uxipirima $=$ amo & hongo comestible \\
\hline xetema $=$ amo & hongo comestible \\
\hline
\end{tabular}


Cuadro 4 - Sustantivos del Tipo 3 con CLN transparentes (II)

\begin{tabular}{|c|c|c|c|}
\hline$=m a$ & $\begin{array}{c}\text { piedra y } \\
\text { frutos duros }\end{array}$ & $=n a$ & avispas, abejas \\
\hline$m a a=m a$ & piedra & hesi $=n a$ & avispa \\
\hline hoko $=m a$ & tipo de seje (bacaba) & karoxo $=n a$ & avispa \\
\hline$m a i=m a$ & fruto de asaí & himoto $=n a$ & abeja \\
\hline$k \tilde{a}$ anari $=m a$ & fruto de batauá & hiporo $=n a$ & abeja \\
\hline$=$ koko & $\begin{array}{c}\text { esférico } \\
\text { (y grande) }\end{array}$ & $=$ koxi & $\begin{array}{c}\text { arasarís } \\
\text { (tucanetes) }\end{array}$ \\
\hline naxi $=$ koko & yuca & aroaroma $=$ koxi & arasarí de azara (ave) \\
\hline mai $=k o k o$ & brea & hãahãama $=k o x i$ & tucanete culik (ave) \\
\hline warapa $=$ koko & brea blanca & krẽkẽkrẽkẽma $=$ koxi & arasarí verde (ave) \\
\hline ãrepa $=k o k o$ & nido de termitas & meremere $=$ koxi & $\begin{array}{l}\text { arasarí cuellinegro } \\
\text { (ave) }\end{array}$ \\
\hline$=\boldsymbol{u}(\boldsymbol{p} \ddot{\boldsymbol{e}})$ & líquidos & $=k i k i$ & $\begin{array}{c}\text { culebras y entidades } \\
\text { serpentiformes }\end{array}$ \\
\hline pata $=u$ & río & horema $=k i k i$ & lombriz intestinal \\
\hline kahe $=u(p \ddot{e})$ & café & aroama $=k i k i$ & serpiente macagua \\
\hline $\operatorname{mau}=u(p \ddot{e})$ & agua & heputu $=k \dot{k} k \dot{t}$ & anguila (mussum) \\
\hline nara $=$ upë & tintura negra & haro $=k i k i$ & collar medicinal \\
\hline aаãma $=$ upë & gasolina & masi $=k i k i$ & $\begin{array}{l}\text { liana usada como } \\
\text { cuerda }\end{array}$ \\
\hline
\end{tabular}

El Cuadro 3 y el Cuadro 4 no deben, sin embargo, dar la falsa idea de que el paradigma de los sustantivos con clasificadores es completamente regular con respecto al número de miembros y a la transparencia de los parámetros semánticos que definen cada categoría. Algunas categorías presentan un paradigma de un solo miembro o de miembros muy heterogéneos. Eso hace con que el sentido de algunos clasificadores sea de difícil atribución, como los del Cuadro 5.

\section{Cuadro 5 - Sustantivos del Tipo 3 con CLN opacos}

\begin{tabular}{|ll|ll|}
\hline \multicolumn{1}{|c|}{$=\boldsymbol{a k a}$} & \multicolumn{1}{c|}{ ¿lengua? } & \multicolumn{1}{c|}{ ¿intestino? } \\
yamara $=a k a$ & raya (pez) & hapaka $=x i$ & olla de barro \\
ama $=a k a$ & fruto (vaina redonda) & nara $=x i$ & achiote, (urucú) \\
waima $=a k a$ & lagarto tejú & oru $=x i$ & marañón (fruto) \\
rema $=a k a$ & lagarto & $x i h o=x i$ & pequeño bagre \\
\hline
\end{tabular}




\begin{tabular}{|c|c|c|c|}
\hline $\begin{array}{l}=\text { moxi } \\
\text { tëpёtёрё }=\text { moxi } \\
\text { hoo }=\text { moxi } \\
k u k u=\text { moxi } \\
\text { pori }=\text { moxi }\end{array}$ & $\begin{array}{l}\text { ¿pene? } \\
\text { trogón (ave) } \\
\text { huito, jagua (fruto) } \\
\text { mono de noche } \\
\text { luz del sol, sol }\end{array}$ & $\begin{array}{l}=\text { mo } \\
\text { hatakoa }=\text { mo } \\
\text { wëtë }=m o \\
\text { maku }=m o \\
\text { hïha }=m o\end{array}$ & $\begin{array}{l}\text { ¿semilla? } \\
\text { chachalaca motmot (ave) } \\
\text { guacamayo (ave) } \\
\text { bagre puyón } \\
\text { abeja }\end{array}$ \\
\hline $\begin{aligned} & =\boldsymbol{m o s i} \\
y \tilde{a n n o} & =m o s i \\
\text { hutu } & =m o s i \\
y \tilde{a n n o} & =m o s i\end{aligned}$ & $\begin{array}{l}\quad \text { ¿? } \\
\text { águila-azor } \\
\text { cielo } \\
\text { avispa }\end{array}$ & $\begin{aligned} & =\text { husi } \\
\text { hora } & =h u s i \\
\text { mau } & =h u s i \\
\text { piriya } & =h u s i\end{aligned}$ & $\begin{array}{l}\text { ¿caparazón? } \\
\text { escarabajo } \\
\text { jícara } \\
\text { viga transversal }\end{array}$ \\
\hline $\begin{aligned} & =\tilde{\boldsymbol{a}} \boldsymbol{h i} \\
\text { paxa } & =\tilde{a} h i\end{aligned}$ & $\begin{array}{l}\therefore ? \\
\text { tipo de cargador }\end{array}$ & $\begin{array}{c}=\text { moka } \\
\text { xama }=\text { moka }\end{array}$ & $\begin{array}{c}\dot{\mathbf{6}} \\
\text { mataguaro (pez) }\end{array}$ \\
\hline
\end{tabular}

Los tres tipos semánticos, el de las ENTIDADES NO CLASIFICADAS, el de las ENTIDADES CLASIFICADAS y el de las PARTES DE LAS ENTIDADES, se manifiestan en subclases de nominales que tienen propiedades morfosintácticas distintas. A continuación presento algunas de esas características que diferencian los tres tipos de sustantivos en YMA.

\subsection{La expresión número}

Una diferencia entre las tres clases de sustantivos hace referencia a la marcación de singular. Todos los sustantivos del Tipo 1 toman la marca $=a$ para expresar el número singular, (5a), mientras que ninguno de los sustantivos del Tipo 2 pueden aparecer con esa marca, (5c). Los sustantivos de Tipo 2 expresan singular sin marcación explícita. En las construcciones en las que el término de parte (Tipo 2) ocurre con el sustantivo que indica la entidad completa (Tipo 1), el sustantivo que indica la parte sustituye la marca singulativa del sustantivo de Tipo 1, como se ejemplifica (5b).

$$
\begin{aligned}
& \text { (5)a. xama }=a \\
& \text { tapir }=\mathrm{SG} \\
& \text { '(Es) un tapir'. } \\
& \text { b. xama }=\varnothing=\mathrm{mahu}=\boldsymbol{\varnothing} \\
& \text { tapir }=\mathrm{SG}=\mathrm{PIE}=\mathbf{S G} \\
& \text { 'El pie del tapir' } \\
& \text { c. }{ }^{*} \text { mahu }=\text { a } \\
& \text { pie }=\mathrm{SG}
\end{aligned}
$$


Los sustantivos con CLN no coaparecen con el morfema de singular $=a,(6)$. La expresión Raíz Libre + CLN, sin otra marca morfológica, expresa que el sustantivo tiene lectura singular, (6).

(6)a. hei $\underline{\text { hoo }}=$ thotho=o

este liana $=\mathbf{C L N}:$ liana $=\mathbf{S G}$

'Esta liana'.

b. kihi $\underline{\text { aroaroama }}=k o x i=$ o

aquel arasarí $=$ CLN:arasarí $=\mathbf{S G}$

'Aquel arasarí (Pteroglossus azara)'.

(7)a. *hei $\underline{\text { hoo }}=$ thotho=a

este liana $={ }_{\mathrm{CLN}}$ :liana $=\mathbf{S G}$

Lectura buscada: 'Esta liana'.

b. *kihi aroaroama $=k o x i=a$

este arasarí $=$ CLN:arasarí $=\mathbf{S G}$

Lectura buscada: 'Aquel arasarí'.

Los tres tipos de sustantivos presentan propiedades similares con respecto al acceso a la marca de dual, =kipë y las de plural, $=p \ddot{e} \mathrm{e}=k i k i^{4}$, pudiendo todos los tipos coocurrir con ellas, aunque con algunas diferencias cuanto al sentido, las que no voy a discutir acá.

\subsection{Independencia y dependencia morfológica}

Una segunda diferencia entre los dos tipos de sustantivos se manifiesta a nivel de cláusula y deriva de una diferencia semántica básica entre ellos: los sustantivos del Tipo 2 tienen como referente la parte de una entidad, son sustantivos inalienables, mientras que los sustantivos del Tipo 1 y del Tipo 3 representan entidades completas y son alienables. Esa relación de dependencia entre la parte y la entidad completa, y la relativa independencia de la entidad discreta se manifiestan gramaticalmente en YMA. En la lengua, los sustantivos del Tipo 1 y del Tipo 3 (holónimos) son palabras que pueden ocurrir sin otra palabra léxica. Son sustantivos alienables y pueden ocurrir con poseedor, (8b), o sin poseedor, (8a), y pueden asimismo aparecer aislados (sin otro elemento léxico) como respuesta simple a un pregunta como ‘¿qué es eso?’, (8a) y (8c).
(8)a. iro $=a$
mono_aullador $=\mathrm{SG}$
'(Es) un mono aullador'.

${ }^{4}$ Con los sustantivos del Tipo 2 , el morfema $=k i k i$ se presenta en su versión reducida $=k i$. 
b. hei ipa iro $=a$

este 1sG.POS mono aullador $=\mathrm{SG}$

'Este es mi mono aullador'.

c. $x a m a=p \ddot{e}$

tapir $=\mathrm{PL}$

'(Son) tapires'.

(9)a. xinaru $=u$

algodón $=$ CLN:algodón

'(Es) algodón'.

b. hei aho xote =he

este 2sG.POS canasto $=\mathrm{CLN}$ :redondo

'Este es tu canasto'.

c. meremere $\quad=k o x i=p \ddot{e}$

arasarí_cuellinegro $=\mathrm{CLN}$ :arasarí $=\mathrm{PL}$

'(Son) arasarís cuellinegro'.

Los sustantivos del Tipo 2 (merónimos o partónimos), mientras tanto, son morfemas ligados que dependen de otros morfemas para ocurrir en un enunciado. Son morfemas que prototípicamente ocurren como parte de frases nominales complejas, y requieren ya sea de otro sustantivo, (10a) y (10b), de un pronombre, (10c), de la marca de clase pei, (10d), o de un verbo que los incorpore, (10e). Tienen un comportamiento por lo tanto similar a los clíticos.

(10)a. $\operatorname{ara}=\varnothing=\boldsymbol{h} \boldsymbol{e}=\boldsymbol{\varnothing}$

guacamaya $=$ SG $=$ CABEZA $=$ SG

'(Es) la cabeza de una guacamaya'.

b. meremere $=k o x i=p \ddot{e}=\boldsymbol{h} \tilde{\boldsymbol{o x}} \boldsymbol{x}=\mathbf{p e ̈}$

arasarí $=$ CLN:arasarí $=\mathrm{PL}=$ pico $=\mathbf{P L}$

'Los picos de los arasarís cuellinegro'.

c. $k a m i=y a=h e=\boldsymbol{o}$

$1=1 \mathrm{sG}=$ cabeza $=\mathbf{S G}$

'Mi cabeza'.

d. pei $=\varnothing=$ mamo $=\boldsymbol{\sigma}$

CLASS $=\mathrm{SG}=\mathrm{OjO}=\mathrm{SG}$

'(Es) su ojo'.

e. $y a=\varnothing=\boldsymbol{h} \boldsymbol{e}=\boldsymbol{o}=\quad$ nia $=k e=m a$

$1 \mathrm{sG}=3 \mathrm{sG}=$ cabeza $=\mathrm{SG}=$ flechar $=\mathrm{PRF}=\mathrm{PST}$

'Le fleché su cabeza'. 


$$
\begin{aligned}
& \text { f. } y a=\varnothing=\text { pok } \boldsymbol{o}=\boldsymbol{p} \ddot{\boldsymbol{e}}=\quad \text { huwe }=r e=m a \\
& 1 \mathrm{SG}=3 \mathrm{SG}=\text { brazo }=\mathrm{PL}=\text { agarrar }=\mathrm{PRF}=\mathrm{PST} \\
& \text { 'Le agarré los brazos'. }
\end{aligned}
$$

\subsection{Las construcciones de genitivo y meronímicas}

Otra diferencia entre los dos tipos de nombres se observa en las construcciones meronímicas y degenitivo. En YMAhay dos FNs estructuralmente distintas que expresan una y otra relación. La relación parte-todo (meronímica) se hace por medio de la yuxtaposición del holónimo (Sustantivo del Tipo 1 o del Tipo 3) y del merónimo (Sustantivo del Tipo 2) sin ninguna marca morfológica adicional. El orden es siempre Entidad Completa + Parte, como en (11) y (12).

(11)a. $m o k o=\varnothing=p o k o=\varnothing$

muchacha $=\mathrm{SG}=\mathrm{BRAZO}=\mathrm{SG}$

'El brazo de la muchacha'.

b. Ararima $=\varnothing=h e=\varnothing$

Ararima $=\mathrm{SG}=$ cabeza $=\mathrm{SG}$

'La cabeza de Ararima'.

c. waro $=p \ddot{e}=p o k o=p \ddot{e}$

hombre $=\mathrm{PL}=$ brazo $=\mathrm{PL}$

'Los brazos de los hombres'.

(12)a. ahõ $\quad=h i=\varnothing=p o k o=\varnothing$

aguacate $=\mathrm{CLN}:$ árbol $=\mathrm{SG}=\mathrm{ramo}=\mathrm{SG}$

'El ramo del árbol de aguacate'.

b. rea $=s i=\varnothing=h e=\varnothing$

roedor $=\mathrm{CLN}$ :pequeño $=\mathrm{SG}=$ cabeza $=\mathrm{SG}$

'La cabeza del roedor'.

c. werehe $=k o k o=\mathrm{pë}=m a m o=p \ddot{e}$

perico $=$ CLN:esférico $=\mathrm{PL}=0 \mathrm{OjO}=\mathrm{PL}$

'Los ojos de los pericos'.

La construcción meronímica donde la $1^{\mathrm{a}} \mathrm{o} 2^{\mathrm{a}}$ persona es el holónimo y el sustantivo del Tipo 2 el merónimo, hace uso de los pronombres personales libres (no posesivos) de $1^{\mathrm{a}}$ y $2^{\mathrm{a}}$ persona en su versión absolutiva (sin la marca de caso ergativo, instrumental o locativo). Los sustantivos del Tipo 2 (la parte) le siguen a esos pronombres en la construcción.

$$
\begin{aligned}
& \text { (13)a. } \text { kami }=y a=p o k o=\varnothing \\
& 1=1 \mathrm{sG}=\text { brazo }=\mathrm{SG} \\
& \text { 'Mi brazo'. }
\end{aligned}
$$


b. $\quad$ kaho $=w a=m a m u=k u$

$2=2 \mathrm{SG}=\mathrm{OjO}=\mathrm{PL}$

'Tus ojos'.

c. $\quad$ kami $=y a m a k i=h e=p \ddot{e}$

$1 \quad=1 \mathrm{PL}=$ cabeza $=\mathrm{PL}$

'Nuestras cabezas'.

d. $k a h o=$ wamaki $=m a h u=p \ddot{e}$

$1=1 \mathrm{PL}=\mathrm{pie}=\mathrm{PL}$

'Los pies de ustedes'.

Por otra parte, a diferencia de las construcciones meronímicas que no requieren marcación morfológica, las construcciones de genitivo (con sustantivos del Tipo 1 o del Tipo 3 en el rol de poseídos) siempre requieren de alguna marca, ya sea un pronombre posesivo cuando la $1^{\mathrm{a}} \mathrm{o} 2^{\mathrm{a}}$ persona singular está en el rol de poseedor (ipa 'mi' y aho 'tu'), ya sea de la marca de genitivo/ poseído $(=e)$ cuando la $3^{\mathrm{a}}$ singular está esta posición.

(14)a. ipa hapaka $=\mathrm{a}$

1sG.POS olla $=$ SG

'Mi olla'.

b. aho ahõ $i=h i=k i p \ddot{~}$

2SG.POS aguacate $=$ CLN:árbol $=\mathrm{dl}$

'Tus dos árboles de aguacate'.

(15)a. kama raa $=\boldsymbol{e}=\operatorname{sih} i=\varnothing$

él $\quad \operatorname{arco}=\mathbf{G E N}=\mathrm{CLN}: \operatorname{arco}=\mathrm{SG}$

'Su arco (de él)'.

b. thuwë poo $=\boldsymbol{e}=p \ddot{e}$

mujer cuchillo $=\mathbf{G E N}=\mathrm{PL}$

'Los cuchillos de la mujer'.

No existen pronombres posesivos para las demás personas gramaticales. Para que las personas de plural (ya sea $1^{\mathrm{a}}, 2^{\mathrm{a}}$ o $3^{\mathrm{a}}$ ) funcionen como poseedores gramaticales de un sustantivo del Tipo 1 o del Tipo 3, se hace necesario que previamente el sustantivo poseído se sujete a una derivación, por medio del morfema $=p \ddot{e}$, que lo convierte en un sustantivo del Tipo 2. Esa "conversión" permite que el sustantivo poseído del Tipo 1 o del Tipo 3 adquiera las propiedades morfosintácticas de los sustantivos del Tipo 2 y que se vuelva un clítico. En la construcción de posesión, la forma derivada se liga al pronombre libre en su versión absolutiva como un enclítico, exactamente como lo hace un sustantivo del Tipo 2. 
(16)a. $\quad$ kami $=$ yamaki=urihi $=\boldsymbol{p} \ddot{\boldsymbol{e}}$

$1=1 \mathrm{DL}=$ tierra $=\mathbf{D E R V}$

'Nuestra tierra (de nosotros dos)'.

b. $k$ aho $=$ wamaki $=$ yano $=\boldsymbol{p} \ddot{\boldsymbol{e}}$

$2=2 \mathrm{PL}=$ casa $=$ DERV

'La casa de ustedes'.

(17)a. $\quad k a m i=y a m a k i=r a s a=s i=p \ddot{e}$

$1=1 \mathrm{PL}=$ pijiguao $={ }_{\mathrm{CLN}}$ :palmera $=\mathbf{D E R V}$

'Nuestras palmeras de pijiguao'.

b. $\quad$ kaho $=$ wamaki $=$ pata $=\boldsymbol{u}=\boldsymbol{p} \ddot{\boldsymbol{e}}$

$2=2 \mathrm{PL}=$ grande $=$ CLN:líquido $=\mathbf{D E R V}$

'Los ríos de ustedes'.

Los sustantivos del Tipo 2 no aceptan los pronombres posesivos ipa y aho, (18), y en las construcciones de todo-parte (meronímicas), el sustantivo del Tipo 2 no recibe la marca de genitivo $=e,(19)$. Tampoco los sustantivos del Tipo 2 coocurren con el morfema derivativo $=p \ddot{e},(20)$.

(18)a. *ipa $=p o k o=\varnothing$

$1 \mathrm{sG} . \mathrm{POS}=$ brazo $=\mathrm{SG}$

Lectura buscada: 'mi brazo'.

b. *aho $=h e=\varnothing$

2sG.POS =cabeza $=\mathrm{SG}$

Lectura buscada: 'tu cabeza'.

(19)a. *Himotona $=p o k o=e$

Himotona $=$ brazo $=$ GEN

Lectura buscada: 'El brazo de Himotona'.

b. *Himotona $=e=$ poko

Himotona $=\mathrm{GEN}=$ brazo

Lectura buscada: 'El brazo de Himotona'.

(20) $\quad$ kami $=y a=h e=p \ddot{e}$

$1 \quad=1 \mathrm{SG}=$ cabeza $=$ DERV

Lectura buscada: 'Mi cabeza'.

\subsection{La incorporación al predicado}

Cuando los sustantivos del Tipo 1 están en el rol de paciente en un enunciado transitivo, o de sujeto en un intransitivo, las marcas de número se incorporan al predicado por un proceso de proclitización de morfemas que son enclíticos en la FN. El rígido orden $\mathrm{PV} / \mathrm{SV}$ en la lengua propició la 
reestructuración morfológica, y permitió que, en nivel de cláusula, la lengua pasara a ser del tipo de marcación en el núcleo. Los sustantivos del Tipo 1, de esta manera, están en correferencia con las marcas de número, las cuales actúan como proformas de $3^{\text {a }}$ persona en el predicado. En los enunciados transitivos en los que la $1^{\mathrm{a}} \mathrm{o} 2^{\mathrm{a}}$ persona son agentes, la incorporación de esos morfemas se hace evidente, (21). La correferencia de las marcas de número incorporadas al predicado con la FN-absolutiva permite que se omita el núcleo nominal de la FN, (21c), e incluso, todo el argumento, (21d).

(21)a. ware $y a=\boldsymbol{k} \boldsymbol{k} \boldsymbol{k}=n i a=r \tilde{a}=r e=m a$

pecarí $1 \mathrm{SG}(\mathrm{A})=\mathbf{3 P L}(\mathbf{P})=$ flechar $=$ DISTR $=$ PRF $=$ PST

'Fleché a los pecarís (una manada de pecarís)'.

b. hei wï $w a=k i p \ddot{\boldsymbol{e}}=t \ddot{e}=r i$

este canasto $2 \mathrm{SG}(\mathrm{A})=\mathbf{3} \mathbf{D L}(\mathbf{P})=1$ levar $=\mathrm{PRF}$

'Lleva [tu] estos dos canastos'.

c. hei $w a=k i p \ddot{\boldsymbol{e}}=t \ddot{e}=r i$

este $2 \mathrm{SG}(\mathrm{A})=\mathbf{3} \mathbf{D L}(\mathbf{P})=1$ levar $=\mathrm{PRF}$

'Llévate éstos'.

d. $\quad w a=k i p \ddot{e}=t \ddot{e}=r i$

$2 \mathrm{SG}(\mathrm{A})=3 \mathrm{DL}(\mathbf{P})=1$ levar $=\mathrm{PRF}$

'Llévatelos'.

Por otra parte, un sustantivo del Tipo 2 es un enclítico que se asocia a un pronombre o un sustantivo del Tipo 1 en una construcción tipo todo - parte, (22). Cuando esta FN compleja ocupa el rol de sujeto (S) o paciente (P) semántico de una cláusula, el sustantivo del Tipo 2 se incorpora obligatoriamente junto con todas las marcas de número (suyas y las del sustantivo que designa el 'todo'.

$$
\begin{array}{lcc}
k a m i & =y a=n \dot{i} & y u r i \\
1 & =1 \mathrm{SG}=\mathrm{ERG} & \text { pez }
\end{array}
$$

Los sustantivos del Tipo 2 no se pueden omitir de la cláusula, (23c), como sí lo lo pueden ser los sustantivos del Tipo 1, (23b).

(23)a. mihi yuri $p \ddot{e}=x i=k i=\quad$ pra $=\mathrm{a}$

ahí pez $3 \mathrm{PL}(\mathrm{S})=$ intestino $=\mathrm{PL}=$ yacer $=$ PRES.EST

'Ahí están tiradas las vísceras de los pescados' (avisando/alertando). 
b. mihi $p \ddot{e}=x i=k i=\quad$ pra $=a$

ahí $3 \mathrm{PL}(\mathrm{s})=$ intestino $=\mathrm{PL}=$ yacer $=$ PRES.EST

'ahí están tiradas sus vísceras (de los pescados)'.

c. *mihi $k i=$ pra $=\mathrm{a}$

ahí $3 \mathrm{PL}(\mathrm{s})=$ yacer $=$ PRES.EST

Lectura buscada: 'ahí están tiradas (las vísceras)'.

Por lo tanto, las marcas de número del sustantivo del Tipo 2 son modificadoras del sustantivo modificado y no marcas correferenciales con un argumento externo al predicado. En cambio, las marcas de número en correferencia con el sustantivo del Tipo 1 son marcas con capacidad pronominal igual que toda la serie de marcas de absolutivo cuando la construcción meronímica está en esta función. Esa perspectiva implica admitir que la entidad completa de la construcción meronímica (el todo) se promueve a argumento central de la cláusula y que, por lo tanto, pasa a ser el sujeto o paciente en la construcción.

Los sustantivos del Tipo 3, mientras tanto, son palabras complejas compuestas de una raíz libre (similar a un sustantivo del Tipo 1) y un clítico con función clasificatoria. Cuando el sustantivo clasificado está en función absolutiva, es solamente la porción clítica del nombre (el CLN) que se incorpora obligatoriamente al predicado, (24). La parte del sustantivo clasificado que es raíz libre nunca se incorpora al predicado sin ser derivada previamente.

(24)a. $k a m i=y a=n \dot{i} \quad$ reã

$1=1 \mathrm{SG}=\mathrm{ERG} \quad$ roedor

$[y a=s i=p \ddot{e}=\quad \text { nia } \quad=r \tilde{a}=r e=m a]_{\text {predicado }}$

$1 \mathrm{SG}(\mathrm{A})=\mathbf{C L N}$ :pequeño(P) $=\mathbf{3 P L}(\mathbf{P})=$ flechar $=\mathrm{DISTR}=\mathrm{PRF}=\mathrm{PST}$

'Fleché a un roedor Proechimys guyannensis'.

b. meremere $\quad[y a=k o x \boldsymbol{i}=\boldsymbol{g}=\quad w a \quad=r e=m a]_{\text {predicado }}$ arasarí $1 \mathrm{SG}(\mathrm{A})=\mathbf{C L N}$ :arasarí $(\mathbf{P})=\mathbf{3 S G}(\mathbf{P})=$ comer $\quad=\mathrm{PRF}=\mathrm{PST}$ 'Comí uno arasarí'.

Por otra parte, cuanto a las posibilidades de omisión en la cláusula mínima, es solamente la porción 'raíz libre' del sustantivo clasificado que puede ser ocultada. Los CLN ocurren obligatoriamente.
(25)a. $y a=s i=p \ddot{e}=$
nia $\quad=r \tilde{a}=r e=m a$
$1 \mathrm{SG}(\mathrm{A})=\mathbf{C L N}$ :pequeño( $\mathbf{P})=\mathbf{3 P L}(\mathbf{P})=$ flechar $=\mathrm{DISTR}=\mathrm{PRF}=\mathrm{PST}$
'Fleché unos roedores Proechimys guyannensis'. 


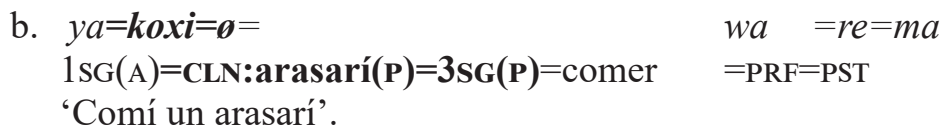

Otras diferencias podrían todavía ser indicadas, como el acceso al rol de agente de cláusula transitiva, exclusivo de algunos sustantivos animados del Tipo 1 y del Tipo 3 e indisponible a todos los del Tipo 2. Sin embargo, por razones de espacio, me limito a esas diferencias ya discutida, las que presento resumidamente en el Cuadro 6.

\section{Cuadro 6 - Propiedades distintivas entre los 3 tipos de sustantivos del YMA}

\begin{tabular}{lccc} 
& Tipo 1 & Tipo 2 & Tipo 3 \\
\hline \hline Requieren de una marca explícita en el singular & $\checkmark$ & $\times$ & $\times$ \\
\hline Pueden tomar marcas de plural & $\checkmark$ & $\checkmark$ & $\checkmark$ \\
\hline Tienen independencia morfológica & $\checkmark$ & $\times$ & $\checkmark$ \\
\hline Se incorporaran al predicado sin adición de morfología & $\times$ & $\checkmark$ & sólo el CLN \\
\hline Conviven con los posesivos ipa 'mi' y aho ‘tu' & $\checkmark$ & $\times$ & $\checkmark$ \\
\hline Cuando la 3 ${ }^{a}$ singular los posee, toman la marca $=e$ & $\checkmark$ & $\times$ & $\checkmark$ \\
\hline Participan de construcciones con el derivativo $=p \ddot{e}$ & $\checkmark$ & $\times$ & $\checkmark$ \\
\hline Pueden tomar el morfema de clase pei & $\times$ & $\checkmark$ & $\times$ \\
\hline Pueden omitirse en la cláusula mínima & $\times$ & $\checkmark$ & sólo la raíz \\
\hline
\end{tabular}

\section{Construcciones meronímicas metafóricas y metonímicas}

Un cuarto tipo de nombres en YMA son los sustantivos compuestos formados por un sustantivo del Tipo 1 y un sustantivo del Tipo 2, en una construcción similar al de (2) y (11), es decir, de todo-parte. Esos sustantivos compuestos, sin embargo, son construcciones metafóricas que no denotan a una parte de un todo, sino que tienen como referente a una entidad completa (26). Se encuentran ejemplos de esta construcción esparcidos por diversos campos semánticos de la lengua, desde los nuevos artefactos traídos por el contacto, hasta referentes presumiblemente más tradicionales. A continuación tenemos ejemplos de esa composición metafórica para designar un pez, (26a), un hongo, (26b), un réptil, (26c), un fruto, (26d), un insecto, (26e), un ave, (26f), una herramienta, (26g), y hasta un evento natural, (26h).

$$
\begin{aligned}
& \text { (26)a. poxe }=h o k o=\varnothing \\
& \text { pecarí }=\text { frente }=\mathrm{SG} \\
& \text { 'Un bagre' } \\
& \text { (lit. 'frente de pecarí'). }
\end{aligned}
$$
e. $\quad$ pore $=$ mamakasi $=\varnothing$
fantasma $=$ párpado $=\mathrm{SG}$
'Luciérnaga'
(lit. 'párpado de fantasma').



b. haya $=a k a=s i=k i$
venado $=$ lengua $=$ piel $=\mathrm{PL}$
'Hongo comestible'
(lit. 'piel de lengua de venado').
f. $\quad$ rixxi $\quad=p o k o=\varnothing$
arpía_mayor $=$ brazo $=\mathrm{SG}$
'Arpía menor'
(lit. 'el brazo de la arpía mayor').
c. yanomama =homotho=ki
yanomami $=$ vértebra $=\mathrm{PL}$
'Lagarto gusano moteado'
(lit. 'vértebras de yanomami').
g. oko $=$ husi $=\varnothing$
cangrejo $=$ caparazón $=\mathrm{SG}$
'Cavador'
(lit. 'caparazón de cangrejo').
d. oko =ehetha $=k i$
cangrejo $=$ puño $=\mathrm{PL}$
'Flor usada como adorno'
(lit. 'puños de cangrejo').
h. ximi =nasipë
perezoso $=$ orina
'Lluvia que pasa rápido'
(lit. 'orina de perezoso').

Algunas construcciones meronímicas pueden denotar a entidades independientes también por medio de una transferencia metonímica. Esas expresiones designan, por ejemplo, adornos hechos de partes de animales o plantas. Los nombres de esos adornos se forman por un sustantivo del Tipo 1 que designa al animal o a la planta de que son hechos los adornos, y por un sustantivo del Tipo 2 que designa la parte específica del animal o planta utilizada en el adorno.
(27)a. mayapa $=\tilde{a} h u=k u$
tucán =región_de_la_cloaca $=\mathrm{PL}$
'Adorno de plumas de tucán'.

b. ara $=x i n a=k \dot{t}$

guacamaya $=$ pluma de la cola $=\mathrm{PL}$

'Adorno de plumas de guacamaya'.

c. paari $=h e s a k a=k i$

pauj=región_occipital $=\mathrm{PL}$

'Adorno de plumas del paují'.

d. wixa $\quad=x i n a=\varnothing$

mono barbudo $=$ cola $=\mathrm{SG}$

'Adorno de cola de mono barbudo'.

En los casos de (27), para la obtención del sentido mencionado en la traducción, tuvo lugar una transferencia semántica por medio de la cual se nombra el objeto con la materia de la cual está hecho. Para nuestro estudio será importante el análisis de la estructura morfológica de esta construcción. Para los ejemplos de (27) asumo que no existen morfemas de singular (ceros morfológicos) entre los sustantivos del Tipo 1 y los sustantivos del Tipo 2. La no atribución de un cero en esta posición se debe a que, con el sentido de 'adorno', las flexiones de número que son abiertamente marcadas (plural y 
dual/paucal) no pueden ocupar ese lugar. Esos morfemas ocurren una única vez en las construcciones meronímicas con este sentido y se ligan solamente a los sustantivos del Tipo 2, (28a). La construcción (28b) es agramatical en el sentido buscado y la única lectura posible es la que se indica en (28c) (el sentido literal).

(28)a. wixa $=x i n a=k \boldsymbol{i}$

mono_barbudo $=$ cola $=\mathbf{P L}$

'Piezas de adorno de cola de mono barbudo'.

b. *wixa =p $\ddot{\boldsymbol{e}}=x i n a=k \dot{t}$

mono_barbudo $=\mathbf{P L}=$ cola $=\mathrm{PL}$

Lectura buscada: 'Piezas de adorno de cola de mono barbudo'.

c. wixa $=\boldsymbol{p} \ddot{\boldsymbol{e}}=x i n a=k \dot{t}$

mono_barbudo $=\mathbf{P L}=$ cola $=\mathrm{PL}$

'Las colas de los monos barbudos' (no se está refiriendo al adorno).

De manera similar a lo que ocurre en la construcción meronímica que designa adornos, en los ejemplos de (26), el espacio designado a los morfemas de número del sustantivo del Tipo 1 en la construcción meronímica prototípica deja de estar disponible en la construcción con sentido metafórico. El rasgo [+entidad independiente] que adquiere la expresión con sentido abstracto explica la reestructuración morfológica por que pasa la construcción. En los ejemplos (29a) y (30a), vemos que la única marca de plural en la construcción meronímica con sentido metafórico está localizada a la derecha del sustantivo del Tipo 2. Las construcciones (29b) y (30b) no pueden ser usadas en sentido metafórico, sólo en su sentido literal (29c) y (30c).

(29)a. poxe $=h o k o=p \ddot{e}$

pecarí $=$ frente $=\mathrm{SG}$

'Unos bagres'

(lit. 'frentes de pecarí').

b. ${ }^{*}$ poxe $=p \ddot{e}=h o k o=p \ddot{e}$

pecarí $=\mathbf{P L}=$ frente $=\mathbf{P L}$

Lectura buscada: 'Unos bagres'

(lit. 'frentes de pecarís').

c. poxe $=p \ddot{e}=h o k o=p \ddot{e}$

pecarí $=\mathbf{P L}=$ frente $=\mathbf{P L}$

'Las frentes de los pecarís'.

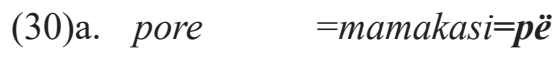

fantasma = párpado $=\mathrm{SG}$

'Luciérnagas'

(lit. 'párpados de fantasma'). 
b. ${ }^{*}$ pore $=\boldsymbol{p} \ddot{\boldsymbol{e}}=$ mamakasi $=\boldsymbol{p} \ddot{\boldsymbol{e}}$

fantasma $=\mathbf{P L}=$ párpado $=\mathbf{P L}$

Lectura buscada: 'luciérnagas'

(lit. 'párpados de fantasmas').

c. pore $=\boldsymbol{p} \ddot{\boldsymbol{e}}=$ mamakasi $=\boldsymbol{p} \ddot{\boldsymbol{e}}$

fantasma $=\mathbf{P L}=$ párpado $=\mathbf{P L}$

'Los párpados de los fantasmas'.

Se debe notar que lo mismo ocurre con los sustantivos con CLN: solamente hay una posición para marcar el número de la entidad (independiente) a la que refiere. Ese espacio no está a la izquierda del CLN, (31c), sino a su derecha, (31b).

(31)a. meremere $=k o x i=\varnothing$

arasarí $\quad=$ CLN:arasarí $=\mathrm{SG}$

'UN arasarí'.una entidad independiente

b. meremere $=k o x i=p \ddot{e}$

arasarí $\quad=$ CLN:arasarí $=\mathrm{PL}$

'Algunos arasarís (Pteroglossus aracari)'.

múltiples entidades

c. * meremere $=\boldsymbol{p} \ddot{\boldsymbol{e}}=k o x i$

arasarí $\quad=\mathrm{PL}=\mathrm{CLN}$ :arasarí

LECTURA BUSCADA: 'UNOS arasarís cuellinegro'.

Otra evidencia de se agrega el rasgo [+entidad independiente] al sentido de la expresión meronímica es el acceso de ese tipo construcción a los pronombres posesivos (ipa 'mi' y aho 'tu') (32a) y (32b), al morfema de poseído $=e,(32 \mathrm{c})$, $\mathrm{y}$ al morfema derivativo $=p \ddot{e}$, (32d).

(32)a. ipa pore $=$ mamakasi $=\varnothing$

1SG.POS fantasma $=$ párpado $=\mathrm{SG}$

'Mi linterna'.

b. aho warõ =wathëmo $=p \ddot{e}$

1sG.POS hombre =testículo=PL

'Tus frutos (que colectaste)'.

c. Ararima oko $=e=$ nahas $i=\varnothing$

Ararima cangrejo $=$ uña $=$ SG

'El tenedor de Ararima'.

d. $k a m i=y a m a k i=w a k a \quad=h u s i=p \ddot{e}$

$1=1 \mathrm{PL}=$ armadillo $=$ caparazón $=$ DERV

'Nuestra televisión'. 
Como vimos en 2.1, esos morfemas están disponibles apenas a los holónimos, o sea sustantivos del Tipo 1 o del Tipo 3. En efecto, estoy sugiriendo que, por su estructura morfológica y comportamiento formal, la construcción metafórica no se distingue de los "legítimos" sustantivos con CLN. Otros contextos igualmente indican una convergencia formal entre las dos construcciones, como el comportamiento de la metáfora cuando está en el rol $\mathrm{P}$ o $\mathrm{S}$ en un enunciado, (33a), y las posibilidades de omisión en la cláusula mínima, (33b). Vimos, en (25), que cuando los sustantivos con CLN están en el rol S o P, también es solamente la parte clítica del sustantivo que se incorpora al predicado y es obligatoria en un predicado verbal mínimo.

\begin{tabular}{|c|c|c|c|}
\hline $\begin{array}{l}\text { kami }=y a=n i \\
1=1 \mathrm{sG}=\mathrm{ERG}\end{array}$ & $\begin{array}{l}\text { haxima } \\
\text { tinamú }\end{array}$ & $\begin{array}{l}{[y a=\text { kohosi }=p \ddot{e}=} \\
1 \mathrm{SG}(\mathrm{A})=\operatorname{lomo}(\mathbf{p})=3 \mathrm{PL}(\mathbf{P})=\end{array}$ & $\begin{array}{l}\text { wa } \\
\text { comer }\end{array}$ \\
\hline
\end{tabular}

b. $y a=k$ ohos $\boldsymbol{i}=\boldsymbol{p} \ddot{\boldsymbol{e}}=\quad$ wa $=i m i$
$1 \mathrm{SG}(\mathrm{A})=\operatorname{lomo}(\mathbf{p})=\mathbf{3 P L}(\mathbf{P})=$ comer $=$ NEG
'No como los frutos de Tetragastris panamensis'.

\subsection{Explicando las metáforas}

En toda transferencia metafórica ocurre un proceso de selección de por lo menos una propiedad del referente expresado por el término en su sentido literal que luego se asocia a una propiedad, también destacada, del referente a ser nombrado con la metáfora (Lakoff y Johnson, 1980: 40). En otras palabras, por un lado, se destaca uno o más rasgos del conjunto total de rasgos semánticos que definen el sentido literal del término y, por el otro, esos rasgos destacados son asociados a rasgos idénticos y también destacados del referente que tiene el término en sentido metafórico. Ahora analizaré algunos ejemplos de construcciones meronímicas con sentido metafórico en YMA y el mecanismo de destaque y extensión de los rasgos semánticos. Empezaré con los casos más simples con respecto al conjunto de rasgos involucrados, casos en los que las metáforas del tipo todo-parte están basadas en un único rasgo que expresa una propiedad física. En (34) presento algunos ejemplos de metáforas en las que los rasgos de forma son los más prominentes.
(34)a.
$\begin{array}{ll}\text { paxo } & =\text { nasi }=\varnothing \\ \text { mono_araña } & =\text { vejiga }=\mathrm{SG}\end{array}$
[+esférico]
'Pelota' (lit. 'vejiga de mono-araña')
b. yaarema $=$ nahasi $=\varnothing$
perezoso $=$ uña $=$ SG $\quad[+$ prolongamiento que
'Especie de pasto' (lit. 'uña del perezoso'). termina en punta] 
c. $i w a=x i n a=\varnothing$
caimán $=$ cola $=$ SG $\quad[+$ tiene protuberancias

'Serrucho'(lit. 'cola de caimán') regularmente distribuidas]

Es difícil suponer, mientras tanto, que solamente una única categoría semántica esté actuando en la operación. En (34a), por ejemplo, aunque el rasgo de forma [+esférico] proporcionado por el sustantivo del Tipo 2 =nasi 'vejiga' se ponga en primer plano, se puede identificar también, con un análisis más detenido, el rasgo de tamaño que es concedido por el sustantivo del Tipo 1 paxo 'mono-araña'. Es decir, el rasgo [+esférico] está modificado por el rasgo secundario [+del tamaño de una vejiga de mono-araña]. La modificación del rasgo secundario [tamaño] se comprueba con construcciones parecidas utilizadas para nombrar diferentes tamaños de pelotas. Note que es el sustantivo del Tipo 1 que promueve las modulaciones en el rasgo [tamaño].
(35)a. $\quad x a m a \quad=n a s i=\varnothing$
tapir $=$ vejiga $=$ SG
'Pelota grande'
(lit. 'VEJIGA DE TAPIR').
b. $x$ oko $=$ nasi $=\varnothing$
oso_hormiguero $=$ vejiga $=\mathrm{SG}$
'Pelota mediana'
(lit. 'VeJiga DE OSO-HORMiguero').

En otros casos, mientras tanto, pueden intervenir rasgos diferentes a los de [forma]. En(36a), por ejemplo, presento una construcción meronímica metafórica utilizada para nombrar un fruto del género Tabernaemontana. Ese fruto tiene la forma ovalada cuando está brotando y adquiere un aspecto perfectamente esférico cuando está maduro. La expresión metafórica que designa ese fruto literalmente tiene el sentido de 'testículo de pecarí. Aunque efectivamente participe en la transferencia metafórica el rasgo [+esférico] o [+ovalado], que provee el sustantivo del Tipo 2, =wathëmo 'testículo', los hablantes nativos reportan que hay otro motivo para que se haya elegido ese determinado sustantivo del Tipo 2, 'testículo', y no otro que también tiene el rasgo [+esférico] en su constitución, como =mamo 'ojo'. Según ellos, la razón de esa elección se debe a que la pulpa de este fruto tiene una textura particular además de presentar una resina pegajosa entre la cáscara y la pulpa. Los testículos de animales, por su parte, tienen una carne de textura particular que es significativamente diferente de las demás partes de su cuerpo. En esta transferencia semántica, por lo tanto, se seleccionan los rasgos de forma [+esférico] y de textura [+textura singular de la carne] del sustantivo del Tipo 2 para la metáfora. Ese sustantivo del Tipo 2 
fue encontrado en otras dos construcciones meronímicas en sentido metafórico que también son usadas para designar frutos. Uno de esos frutos también es del género Tabernaemontana (36b). Los tres frutos son esféricos, presentan la resina pegajosa en la cáscara y la textura de su pulpa se considera particular.

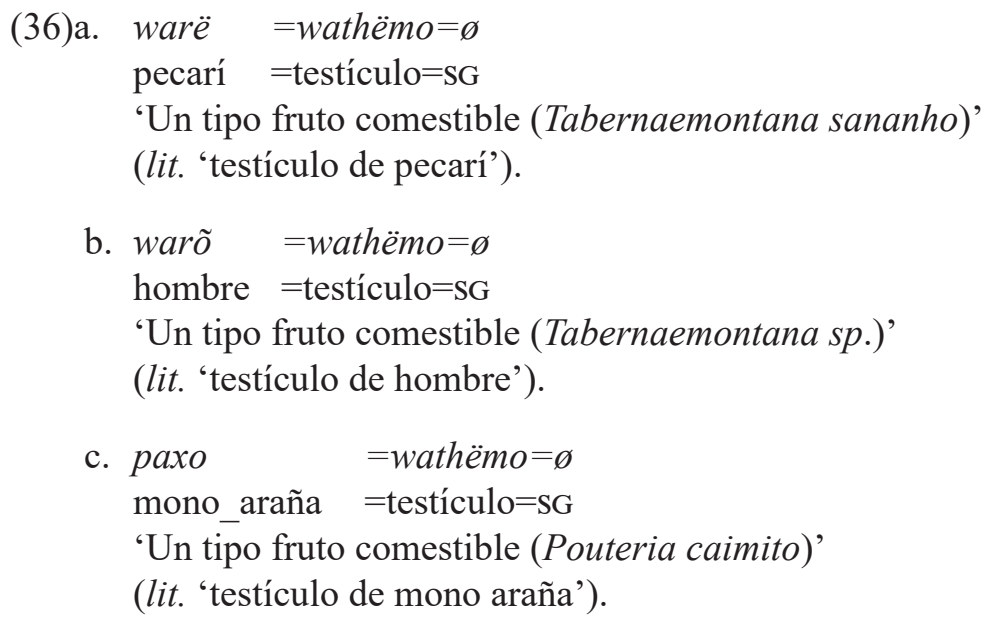

En otros casos, la información transferida metafóricamente se asocia a una metonimia. El hongo que recibe el nombre de 'oreja de Tiriri', (37), por ejemplo, además de su forma similar a una oreja [+protuberancia lateral][+bordes redondeados], también es utilizado como medicina contra los padecimientos de los que están siendo atacados por el 'espíritu de la obscuridad', Tiriri. Éste es un espíritu antropófago que acomete a los que infringieron los tabús de incesto. Para el tratamiento, se quema el hongo y se la hace oler el humo al paciente. La relación de contigüidad entre el referente fuente y el referente blanco de la transferencia metonímica es del tipo agente patológico-medicina/antídoto.

$$
\begin{array}{ll}
\text { titiri } & =y a m a k a=k \dot{ } \\
\text { personaje_mítico } & =\text { oreja }=\mathrm{PL} \\
\text { 'Hongo medicinal / de hechicería (Amauroderma camerarium)' }
\end{array}
$$

En algunos casos los rasgos semánticos transferidos en la metonimia mezclan información sobre la historia y ecología de la región. Ese es el caso de la expresión meronímica que designa al 'pez ángel', una especie de la familia de los cíclidos (de la tilapia) con poco interés económico para los yanomami. La expresión que designa ese pez literalmente significa 'esperma de minero', (38). Según las explicaciones unánimes de los hablantes nativos entrevistados, la metáfora se basa en las explicaciones sobre la ecología de los ríos y lagunas de la región. De acuerdo con los yanomama, y por alguna razón desconocida, el 'pez ángel' (Pterophyllum altum) se reprodujo de manera extraordinaria en los enormes hoyos dejados por los mineros que invadieron Papiu en los fines de los 
años 1980 y que hoy son lagunas eventualmente utilizadas como sitio de pesca. Según las generaciones más antiguas, los yanomami ya conocían este pez, pero era mucho menos abundante. La especie era nombrada con el término $p o o=k o s i$ que designa de manera genérica a todas las diferentes especies de la numerosa familia de los cíclidos.

\section{(38) karĩpero =moupë \\ minero =esperma \\ 'Pez ángel' (lit. 'esperma de minero').}

En otros casos, para identificar los rasgos que son transferidos en la metáfora es necesario recurrir a informaciones de la mitología yanomami. El término para nombrar la gasolina en YMA es un ejemplo, (39). En este caso los rasgos transferidos en la metáfora son [+líquido] [+inflamable] y posiblemente [+amarillo]. Los rasgos [+líquido] y [+amarillo] se los provee en la transferencia el sustantivo del Tipo 2 =nasi 'orina' con su sentido abstraído de 'líquido' o 'líquido amarillo'. Sin embargo, para identificar el rasgo [+inflamable] y, por lo tanto, "entender" toda la metáfora, se hace necesario saber que Herona es el nombre de un personaje de la mitología yanomami que atacó de manera implacable a los yanomami waika=pë con su orina inflamable/corrosiva en el tiempo mitológico. En resumen, la historia mitológica cuenta que Herona olía muy mal y que por ello los waika=pë nunca le invitaban a fiestas reahu. Cuando Herona se dio cuenta que los waika=pë estaban organizando una nueva fiesta, él decidió vengarse. Primero esperó que los hombres salieran de cacería ceremonial, henimuu, y cuando en la casa estaban solo las mujeres, niños y ancianos, se acercó al sitio y empezó a lanzar su orina que calcinó inmediatamente a todos los habitantes. Se dice que su orina era tan potentemente inflamable que cuando los hombres regresaron de la cacería no encontraron ni las cenizas de los muertos preservadas.

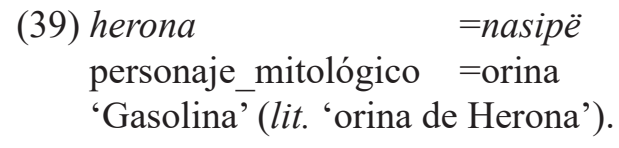

Otro ejemplo similar que recurre a una referencia mitológica para entender la construcción meronímica es el término utilizado para 'cavador', (40). En la mitología yanomami, Terema fue una joven muchacha que no obedeció las instrucciones de su madre de mantener las manos metidas debajo de las axilas durante los días de guardar durante la primera menstruación. Debido a la infracción de la regla, los dedos de una de sus manos empezaron a pegarse uno al otro, las uñas empezaron a crecer hasta que su mano se convirtió en una garra similar a la del armadillo gigante. Cuando le sucedió eso, la muchacha escondió 
su deformación manteniendo sus manos en las axilas. De forma secreta, la muchacha descubre que su mano-garra tiene ciertos usos, como tallar ramas y agarrar cangrejos, y por eso empieza a afilar constantemente su uña en una piedra, pero siempre en secreto. Cierta vez sale a recolectar frutos con su hermana, su cuñado y su hija pequeña. En la recolección ocurrió un accidente y la hija de su hermana es herida por la mano de Terema. Cuando la niña empieza a llorar, la hermana se enfurece con Terema. Terema entonces clava sus uñas en su cuñado y su hermana, los mata, les chupa toda la sangre, los corta en pedacitos y oculta sus restos en el fondo de un canasto con frutas, hai kiki. Otros miembros de la comunidad después descubren el acto antropofágico y, por medio de una trampa logran lanzar a Terema al fuego y matarla (Albert, 1990: 471-2, en Wilbert y Simoneau (eds.)). Obviamente, que ese tipo de referencia a la mitología, (39) y (40), o a la historia, (38), imprime un cierto "riesgo" a la vitalidad plena de la metáfora. Es decir, para que la expresión sea reconocida como una metáfora es necesario que el hablante pueda reconocer el 'sentido literal' de ese término; y para identificar el 'sentido literal' del término es necesario, a su vez, conocer esas referencias mitológicas. Si no se reconoce el 'sentido literal', la metáfora está muerta. Efectivamente, muchos niños y algunos jóvenes entrevistados no conocían la historia de Terema y mucho menos pudieron explicar el porqué del nombre 'uña de Terema'. Cabe mencionar que hay otros sinónimos que son usados de forma alterna para designar esta herramienta agrícola traída por los extranjeros. En (41), por ejemplo, presento otra construcción metafórica (también una metáfora de forma) usada con el sentido de 'cavador'. Sin embargo, el término de (40) es hoy el sinónimo más usado en Papiu para designar el 'cavador' por todas las generaciones, incluso por las que todavía desconocen la historia de Terema.

$$
\begin{aligned}
& \text { (40) } \text { terema =nahasi }=\varnothing \\
& \text { personaje_mitológico }=u n ̃ a=S G \\
& \text { 'Cavador' } \\
& \text { (lit. 'uña de Terema'). }
\end{aligned}
$$

(41) oko $\quad=h u s i=\varnothing$

cangrejo $=$ caparazón $=\mathrm{SG}$

'Cavador'

(lit. 'caparazón de cangrejo').

Para algunos hablantes, por lo tanto, la expresión terema=nahasi es una expresión que en su sentido literal nombra al referente 'cavador', así como herona=nasipë significa simplemente 'gasolina'. Sin embargo, aunque la metáfora no sea completamente recuperable para esos hablantes, estoy asumiendo que en la construcción metafórica los rasgos seleccionados por el 
sustantivo del Tipo 2 se mantienen, aunque la metáfora completa ya no sea transparente. Aunque el sentido literal original ('uña de la personaje mitológica Terema') no exista para todos los hablantes, algunos rasgos que se destacarían en la construcción meronímica potencialmente pueden todavía ser preservados. Eso es posible porque los rasgos semánticos prototípicamente asociados a los sustantivos del Tipo 2 en las transferencias semánticas son rasgos que expresan propiedades fisicas del referente. Esas propiedades son, por lo tanto, recuperables por la experiencia objetiva del hablante, aun cuando la metáfora ha muerto.

Procesos similares de obscurecimiento del significado han ocurrido en otras muchas construcciones que originalmente eran una metáfora de una construcción meronímica literal. Ese puede ser el caso de expresiones que formalmente se parecen a una expresión meronímica, porque incluyen en su estructura a un clítico que es un sustantivo del Tipo 2 ligado a una raíz libre, pero que no tienen un sentido literal ni metafórico claramente identificables, (42). Este tipo de construcciones es relativamente numeroso en la lengua. Note que en todos los casos de (42), quizás con excepción de (42f) y (42g), se puede proponer una metáfora de forma que incluye un sustantivo del Tipo 2. Es decir, los pares 'el pene'/'el rayo del sol', 'cabeza'/‘fruto redondo', 'intestino'/‘lombriz de tierra', 'lengua'/'raya', 'lengua'/ 'vaina plana y redondeada' tienen rasgos de forma similares o mínimamente relacionables.
(42)a. pori $=$ moxi $=\varnothing$
$\mathrm{xxx}=$ pene $=\mathrm{SG}$
'Luz del sol', 'rayo de sol'
(lit. 'pene de $\mathrm{xxx}^{\prime}$ ').
b. $\begin{aligned} \text { xõra } & =h e=\varnothing \\ \mathrm{xxx} & =\text { cabeza }=\mathrm{SG}\end{aligned}$
'Fruto redondo de un árbol'
(lit. 'cabeza de $\mathrm{xxx}$ ')
c. ikõroma $=x i=k \dot{t}$
$\mathrm{xxx}=$ intestino $=\mathrm{SG}$
'Lombriz de tierra (chica)'
(lit. 'intestino de $\mathrm{xxx}$ ')
d. yãmara $=a k a=\varnothing$
$\mathrm{xxx}=$ lengua $=\mathrm{SG}$
'Raya' (pez)
(lit. 'lengua de xxx').
e. $a m a=a k a=\varnothing$
$\mathrm{xxx}=$ lengua $=\mathrm{SG}$
'Vaina de un árbol'
(lit. 'lengua de xxx')

f. sitipari $=h u s i=\varnothing$

$\mathrm{xxx}=$ caparazón $=\mathrm{SG}$

'Saltador' (ave)

(lit. 'caparazón de xxx'???).

g. hiyomori $=$ moxi $=\varnothing$

$\mathrm{xxx}=$ pene $=\mathrm{SG}$

'Formicario capirrojo' (ave)

(lit. 'pene de xxx'???).

h. kopetema $=$ manaxi $=\varnothing$

$\mathrm{xxx}=$ bulto $=\mathrm{SG}$

'Especie de termita'

(lit. 'bulto de xxx'???).

En otros casos, aunque se pueda identificar los constituyentes de la construcción meronímica, el sentido literal que se puede atribuir a esa construcción es polémico, y muchas veces discutido por los hablantes, (43). En 
esos casos, es posible que transferencias metafóricas y metonímicas, basadas en rasgos no solamente de [forma], hayan ocurrido originalmente pero que ya no son reconocibles sincrónicamente. El obscurecimiento de los rastros de esas transferencias genera la disputa sobre el sentido literal y metafórico que el investigador puede atribuir a las expresiones.

(43)a. hoo =moxi=ki

puma_sobrenatural $=$ pene $=\mathrm{PL}$

'Coral' (lit. 'pene del puma sobrenatural'?).

b. sirosiro $^{5}=u s i=k \dot{ }$

golondrina $=$ tibia/miembros_inferiores $=\mathrm{PL}$

'Cachipolla, libélula (Libelulidae)' (lit. 'tibia de golondrina'?).

c. nara $=x i=\varnothing$

zarigüeya $=$ intestino $=\mathrm{SG}$

'Fruto de achiote' (lit. 'intestino de zarigüeya ${ }^{6}$ '?).

d. wãro $=u=\varnothing$

hombre $=$ tibia/pierna $=\mathrm{SG}$

'Fruto comestible (Couepia caryophylloides)' (lit. 'tibia de hombre'?).

e. paxo $=u=k u$

mono_araña $=$ tibia/miembros $=\mathrm{PL}$

'Insecto palo'/ 'mantis' (lit. 'miembros de mono araña'?).

Las construcciones presentadas en (42) y (43) son metáforas muertas. Vimos en (40), un ejemplo de metáfora que está viva para algunos hablantes pero muerta para otros. Vimos en ese caso que, aún para los hablantes que no reconocen la metáfora, la forma no es completamente obscura semánticamente porque los rasgos semánticos que aportan el sustantivo del Tipo 2 de la construcción (sustantivo que es la parte reconocible de la expresión) son rasgos que expresan propiedades físicas, principalmente forma.

\section{Cuando metáforas clasifican: gramaticalización de merónimos en CLN}

Vimos anteriormente que las construcciones meronímicas pueden ser utilizadas d manera metafórica para nombrar entidades independientes y que esas construcciones no se distinguen formalmente de un sustantivo con

\footnotetext{
${ }^{5}$ Esa forma estaría con la [s] de =usi asimilada. La forma para 'golondrina' sin asimilación es xiroxiro.

${ }^{6}$ En un episodio de la mitología yanomami, es con la sangre del zarigüeya que los animales adquirieron el rojo de sus plumas, piel, escamas o ojos.
} 
CLN. En este apartado, mostraré cómo esta indistinción formal permitió que los sustantivos del Tipo 2, que forman parte de esas construcciones, se usaran en contextos no metafóricos, como cualquier otro CLN canónico de la lengua que tiene la propiedad de expresar una categoría clasificatoria en la que se inscriben diversos referentes. Mi argumento va a involucrar la forma $=n a$, sustantivo del Tipo 2, que en su uso como merónimo significa 'diente' y en su uso como CLN es utilizado en 47 sustantivos que designan 'abejas', 'avispas', 'tábanos', 'hormigas', 'ortigas', 'frutos con espino', 'planta de hojas puntiagudas' y 'peces con diente prominente'. Además de su productividad, esta forma es particularmente interesante para nuestro estudio porque permite reconstruir con detalles las diversas etapas de su gramaticalización. La forma $=n a$ ocurre en construcciones meronímicas literales (que es el contexto fuente de la gramaticalización), en construcciones meronímicas metafóricas (que es el contexto puente de ese proceso y el contexto clave de cambio), y en construcciones no meronímicas con sentido clasificatorio (que es el contexto blanco del proceso de gramaticalización). En (44) presento este sustantivo en el contexto fuente de la gramaticalización, es decir, en su uso literal como parte dentro de la construcción todo-parte.

(44) a. hee $=\varnothing=n a=\varnothing$

murciélago $=\mathrm{SG}=$ diente $=\mathrm{SG}$

'El diente del murciélago'.

b. uhuru $=\varnothing=n a=\varnothing$

niño $=\mathrm{SG}=$ diente $=\mathrm{SG}$

'El diente del niño'.

Como mencioné, el contexto puente en la gramaticalización es la construcción meronímica con el sentido metafórico, usada para designar entidades independientes. En ese contexto la forma pierde algunos rasgos semánticos léxicos y resalta otros que expresan una propiedad característica del referente; su sentido transferido es más abstracto que su sentido léxico. Vimos en §3.4.2 que el rasgo destacado en este caso es el rasgo funcional [+que pica] derivado metafóricamente del rasgo de [ + sirve para morder] presente en el conjunto de rasgos del sentido literal de 'diente'. (45)

(45) hee $\quad=n a=\varnothing$

murciélago $=$ diente $=\mathrm{SG}$

'Fruto espinoso' (Centrolobium paraense Tul.) (lit. 'diente de murciélago').

El contexto de cambio de la forma se observa cuando la construcción metafórica se reproduce y nombra diversos referentes que pueden ser caracterizados por medio de la misma propiedad destacada. Es decir, la metáfora 
se replica para nombrar a otros sustantivos que presentan el rasgo destacado. Este proceso provoca dos cambios importantes en la semántica del sustantivo gramaticalizado. Por un lado, con la ampliación del número de referentes similares, se consolida el sentido de la categoría abstracta destacada en la metáfora. Todos los referentes de las construcciones metafóricas son 'entidades que pican'. Por otro lado, esos diferentes referentes pueden presentar otras propiedades en común que no eran partes del sentido del merónimo fuente. En los casos de (46c), (46d) y (46e), por ejemplo, las expresiones metafóricas designan entidades 'que pican' pero esas entidades también tienen un conjunto de propiedades comunes que las distingue de otras entidades, como los rasgos [+animado] [+ser pequeño], [+seis patas], [+que vuela/tiene alas], [+que vive en colmena], etc. Ese conjunto de rasgos pasan a ser parte del sentido de la forma meronímica $=n a$.

$$
\begin{aligned}
& \text { (46)a. pore }=n a=\varnothing \\
& \text { fantasma }=\text { diente }=\mathrm{SG} \\
& \text { 'Hormiga roja'. } \\
& \text { (lit. 'diente de fantasma'). } \\
& \text { b. ira }=n a=k \dot{t} \\
& \text { jaguar }=\text { diente }=\mathrm{PL} \\
& \text { 'Ortiga (Urera baccifera)' } \\
& \text { (lit. 'dientes de jaguar'). } \\
& \text { c. haya }=n a=\varnothing \\
& \text { venado }=\text { diente }=\mathrm{SG} \\
& \text { 'Tábano' } \\
& \text { (lit. 'diente de venado'). } \\
& \text { d. opo }=s i=n a=\varnothing \\
& \text { cucaracha }=\text { CLN:pequeño }=\text { diente }=S G \\
& \text { 'Avispa (Vespoidea)' } \\
& \text { (lit. 'diente de cucaracha'). }
\end{aligned}
$$

Así, en ese proceso de replicación de la metáfora, la forma monocategorial $=n a$ 'que pica' empieza a adquirir otros rasgos semánticos que se alejan del sentido original. Con los nuevos rasgos la forma $=n a$ aparece en contextos diferentes de los meronímicos con sentido metafórico. Ese es el contexto final del camino de gramaticalización en el que la forma está completamente gramaticalizada y su sentido como CLN consolidado, (47).

(47) a. tixopoma $=n a=\varnothing$

abeja $=$ CLN:abeja/avispa/ortiga $=\mathrm{SG}$

'Especie de abeja (Apoidea)'. 
b. kopina $=n a=\varnothing$

avispa $=$ CLN:abeja/avispa/ortiga $=$ SG

'Especie de avispa'.

c. kuriro $=n a=\varnothing$

avispa $=$ CLN:abeja/avispa/ortiga $=\mathrm{SG}$

'Especie de avispa'.

d. $a p i \quad=n a=k i$

ortiga $=$ CLN:abeja/avispa/ortiga $=$ PL

'Especie de ortiga medicinal'.

El CLN =na puede ligarse a todas las formas libres producto de los procesos derivacionales de la lengua. En (48a) tenemos un verbo adjetival nominalizado con - rima; en (48b) vemos un subtipo de la nominalización con - rima, en el que el verbo adjetival tiene incorporado un sustantivo del Tipo 2; en (48c) tenemos la nominalización con -tima que designa agente frecuente; el verbo también tiene un sustantivo incorporado, pero en este caso es una raíz del Tipo 1 y está en función absolutiva en el predicado nominalizado; finalmente en (48d) y (48e) se ilustran dos nominalizaciones con $-m a$, un morfema derivativo más flexible que puede ser aplicado a un verbo adjetival (48d) y un verbo de proceso (48e), en ambos casos con un sustantivo incorporado.

(48)a. puuxi-rima $=n a=\varnothing$

ser_pequeño-DERV $=$ CLN:abeja/avispa/ortiga $=$ SG

'Especie avispa (Vespoidea)' (lit. 'avispa-pequeña').

b. kohosi-ahu-rima $=n a=\varnothing$

abdomen-estar_comprimido-DERV $=$ CLN:abeja/avispa/ortiga $=\mathrm{SG}$

'Especie avispa (Vespoidea)'. (lit. 'avispa-abdomen-comprimido').

c. xipë-wa-tima $=n a=\varnothing$

heces-comer-DERV $=$ CLN:abeja/avispa/ortiga $=$ SG

'Especie de abeja (Apoidea)' (lit. 'abeja-comedora-de-heces').

d. oraka-rape-ma $=n a=\varnothing$

entrada_de_la_colmena-ser_largo-DERV $=$ CLN:abeja/avispa/ortiga $=\mathrm{SG}$

'Especie avispa (Vespoidea)' (lit. 'avispa-entrada-de-la-colmena-larga').

e. mamo-yahayë-ma $=n a=\varnothing$

ojo-arrancar-DERV $=$ CLN:abeja/avispa/ortiga $=\mathrm{SG}$

'Especie avispa (Vespoidea) (lit. 'avispa-ojo-arrancado').

Una evidencia adicional que demuestra que la forma $=n a$ adquirió otros rasgos semánticos al gramaticalizarse son los casos en el que el sustantivo 
que toma ese CLN denota a especies de abejas sin aguijón, como son las abejas nativas del género Melípona y Trigona, las cuales en efecto son las más comunes en la región. Eso es evidencia de que el sentido se extendió desde las especies de la familia Vespoidea (avispas con aguijón) hacia a las especies de la familia Apoidae (abejas) que incluye los géneros sin aguijón, mencionados anteriormente. Note además que las metáforas con el sustantivo del Tipo 2 =na 'diente' de (46), que son los contextos puente y de cambio de la gramaticalización, refieren solamente a especies de avispas y no de abejas. La extensión del uso del CLN hacia los sustantivos que designan abejas solo fue posible cuando este CLN ya estaba resemantizado con los rasgos [+animado] [+pequeño ser], [ + seis patas], [+que vuela/tiene alas], [+que vive en colmena], que la forma adquirió en el contexto de cambio, cuando la metáfora con $=n a$ se replicó a sustantivos que nombran referentes diferentes pero similares. En (49) presento dos ejemplos de sustantivos que tienen como referentes abejas sin aguijón, una del género Melípona, (49a), y otra del genero Trigona, (49b).

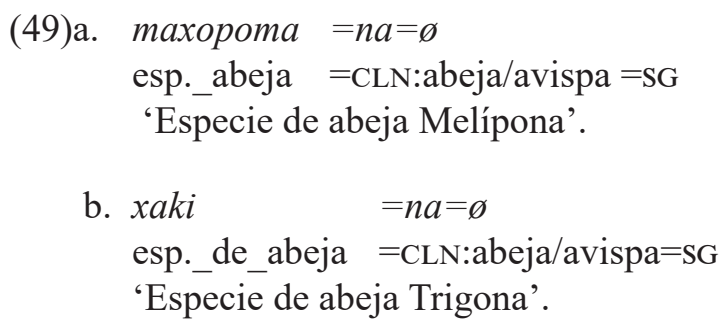

Debo mencionar que no es posible recrear un camino de gramaticalización tan detallado para todos los sustantivos del Tipo 2. El caso de $=n a$ es sui generis porque sincrónicamente la forma aparece en varios estados del proceso. En cambio, con otros CLN solamente podemos ver el inicio del proceso y con otros sólo el final y no los pasos intermedios. Un ejemplo del inicio del proceso lo ilustra la forma =wathëmo que prototípicamente designa 'testículo' en la anatomía humana y animal. Este sustantivo del Tipo 2 ocurre en tres construcciones metafóricas que designan los frutos de dos especies del género Tabernaemontana (la familia de las Apocináceas), (36a) y (36b), y el de una especie de la familia de las Sapotáceas, (36c). Los rasgos destacados en las tres construcciones refieren a la forma [+esférico] y la textura $[+$ pulpa de textura singular] del fruto, como vimos en \$3.4.2. En los ejemplos de (36), se puede observar que los sustantivos participan de construcciones metafóricas y que la forma $=$ wathëmo todavía no se es parte de una construcción no meronímica. La forma está, por lo tanto, a un paso de volverse un legítimo CLN aunque semánticamente ya presenta propiedades características de los CLN, como la función de representar a una categoría en la que se inscriben referentes similares. 
En un estado similar está el sustantivo del Tipo 2 =mamo usado con sustantivos que designana diversos frutos esféricos y pequeños. Como =wathëmo, esta forma aparece solamente en construcciones meronímicas metafóricas, (50). Aunque la gramaticalización de esas formas no se ha completado, las voy a considerar como CLN debido a la imposibilidad de distinguirlas formalmente de sustantivos del Tipo 2 plenamente gramaticalizados como CLN o de CLN que tuvieron origen distinto.
(50)a. pokara $=m a m o=\varnothing$
corcovado(ave) $=\mathrm{ojo}=\mathrm{SG}$
'Fruto (Solanum $s p$ )
(lit. 'ojo de corcovado').

b. totori $=$ mamo $=\varnothing$

tortuga terrestre $=\mathrm{OjO}=\mathrm{SG}$

'Fruto comestible'

(lit. 'ojo de tortuga')'.

c. $x a m a=m a m o=\varnothing$

tapir $=\mathrm{ojo}=\mathrm{SG}$

'Fruto (Cyperus sp)

(lit. 'ojo de tapir')'.

d. yãpi =mamo $=\varnothing$

trompetero_aligrís $=\mathrm{ojo}=\mathrm{SG}$

'Fruto (Margaritaria nobilis)

(lit. 'ojo de trompetero aligrís')'.

e. $p o o=m a m o=\varnothing$

cuchillo $=\mathrm{Ojo}=\mathrm{SG}$

'Fruto (Salpichlaena volubilis)

(lit. 'ojo/tornillo de cuchillo').

f. patixi $=$ mamo $=\varnothing$

cuchillo $=\mathrm{ojo}=\mathrm{SG}$

'Fruto (Salpichlaena volubilis)

(lit. 'ojo/tornillo de cuchillo').

Por último, menciono que la gramaticalización del sustantivo del Tipo 2 $=n a$ 'diente' como CLN está tan avanzada que éste puede incluso ser observado en construcciones meronímicas metafóricas con otros sustantivos del Tipo 2: =moxi 'pene', (51a), =mahu 'pie', (51b), =nasi 'vejiga', (51c). Este contexto demuestra otra vez que la forma está completamente recategorizada como CLN. Note que este contexto es el inicio del camino de gramaticalización de los sustantivos del Tipo 2 en esas construcciones. 


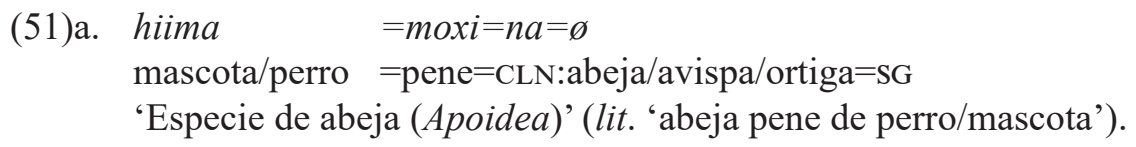

b. totori $=m a h u=n a=\varnothing$

tortuga_terrestre $=$ pata/pie $=$ CLN:abeja/avispa/ortiga $=$ SG

'Especie de abeja (Apoidea)' (lit. 'abeja pata de tortuga').

c. uhuru $=n a s i=n a=\varnothing$

niño $=$ vejiga $=$ CLN:abeja/avispa/ortiga $=\mathrm{SG}$

'Especie de abeja (Apoidea)' (lit. 'abeja vejiga de niño').

\section{Comentarios finales}

En este trabajo discutí algunas de las propiedades formales que definen las subclases nominales en YMA. Vimos que, de acuerdo con esos parámetros formales, también deben ser incluidos en el paradigma de sustantivos con CLN las construcciones meronímicas que designan metafóricamente a una entidad independiente. Vimos como esa construcción fue la ruta que, por un lado, permitió la resemantización de las formas hasta que llegaran a ser un CLN nominal típico, y, por otro lado, llevó posiblemente al oscurecimiento semántico de muchas formas que ocupan la posición morfológica de CLN.

Esta construcción metafórica no da cuenta, sin embargo, de explicar el origen de todos los CLN del YMA. Posiblemente, algunos clasificadores que provienen incluso de merónimos pasaron por un camino de gramaticalización distinto del presentado en este trabajo, como los clasificadores =hanaki (para arbustos), $=s i$ (para palmeras y plantas de fibra útil) y $=m o$ (para algunos frutos $\mathrm{y}$ objetos pequeños). Es posible que las formas meronímicas cognadas $=$ hanaki (hoja), $=s i$ (piel) y $=m o$ (semilla) se gramaticalizaron en CLN por medio de una extensión metonímica, distinta de la mencionada metafórica. Por otra parte, CLN muy frecuentes como $=h i,=$ thotho, $=u$, pasaron asimismo por proceso de gramaticalización muy distinto del descrito acá. Ambos procesos deben ser objeto de investigaciones futuras.

\section{Referencias}

Aikhenvald, Alexandra Y. 2003. Classifiers. A typology of noun categorization devices. Oxford: Oxford University Press.

Grinevald, Colette y Seifart, Frank. 2004. "Noun classes in African and Amazonian languages: towards a comparison". En Linguistic Typology, 8, 243-285.

Heine, B., Claudi, U. y Hünnemeyer, F. 1991. Grammaticalization - A Conceptual Framework. Chicago: The University of Chicago Press. 
Heine, B. y T. Kuteva. 2002. World Lexicon of Grammaticalization. Cambridge: Cambridge University Press.

Heine, B. y T. Kuteva. 2006. The genesis of grammar: A reconstruction. Oxford: Oxford University Press.

Hopper, P. J. y E. C. Traugott. 1993. Grammaticalization, Cambridge: Cambridge University Press. Some Preliminaries.

Lakoff, G. y M Johnson. 1986. Metáforas de la vida cotidiana. Madrid: Ediciones Cátedra.

WiLbert, J. y K. SimoneAu, (eds.). 1990. Folk Literature of the Yanomami Indians. Los Ángeles: University of California.

Data recebimento: 12/02/2014.

Data aceite: 18/04/2014. 